Check for updates

Cite this: Mater. Adv., 2020 1, 1835

Received 11th May 2020 Accepted 22nd July 2020

DOI: $10.1039 / \mathrm{d} 0 \mathrm{ma00295j}$

rsc.li/materials-advances

\title{
Iron oxide nanoparticle incorporated cement mortar composite: correlation between physico- chemical and physico-mechanical properties $\dagger$
}

\author{
Mohammad Valizadeh Kiamahalleh, a Abbas Alishah, ${ }^{\mathrm{b}}$ Fereshteh Yousefi, \\ Saeid Hojjati Astani, ${ }^{b}$ Aliakbar Gholampour*d and \\ Meisam Valizadeh Kiamahalleh (iD *ef
}

\begin{abstract}
It is now well-understood that incorporation of nanoparticles can enhance the physico-mechanical properties of cement mortar composites. However, there is still little information on the influence of the dosage and chemistry of nanoparticles on the physico-chemical properties of the composites. In this paper, nano-modified cement mortar composites containing 0.0, 2.0, 2.5 and 3.0 wt\% of iron oxide (IO) nanoparticles were prepared and their mechanical properties including compressive and flexural strengths were investigated. The results show that the influence of nanoparticle addition is mainly on the growth and change of the calcium silicate hydrate $(\mathrm{C}-\mathrm{S}-\mathrm{H})$ crystals, which ultimately has an impact on the mechanical properties of the composite. The microstructure and morphology of the composites characterized using scanning electron microscopy (SEM) have shown that composites containing 10 have a more compact microstructure with no micro-cracks compared to the plain mortar composite. It is also shown that a composite containing $2.5 \mathrm{wt} \% 10$ exhibits the highest compressive and flexural strengths. It is found that the 10 nanoparticle at $2.5 \mathrm{wt} \%$ dosage not only prevents the formation and propagation of micro-cracks, but also contributes to the improvement of the accessibility of the water molecules to the $1 \mathrm{O}$ oxygen groups and cement $\mathrm{C}-\mathrm{S}-\mathrm{H}$. These findings are promising by establishing correlations between the physico-chemical and physico-mechanical properties of IO-reinforced cement mortar composites, which contribute toward using 10 to improve the mechanical properties of cement mortar composites.
\end{abstract}

\section{Introduction}

Ordinary Portland cement has been widely used as a binder material in the production of conventional concrete. ${ }^{1,2}$ Owing to the low tensile properties of concrete, several studies have been conducted to modify the microstructure and quality of the concrete materials. ${ }^{3}$ In recent years, researchers have focused on using nanoparticles in the production of concrete. ${ }^{4-7}$

\footnotetext{
${ }^{a}$ Faculty of Chemical Engineering, Babol Noshirvani University of Technology, Babol, 47148-71167, Iran

${ }^{b}$ Technical Department, Mazandaran Cement Company, Neka, 48411-19797, Iran

${ }^{c}$ Department of Chemistry, Babol Noshirvani University of Technology, Babol, 47148-71167, Iran

${ }^{d}$ College of Science and Engineering, Flinders University, SA, 5042, Australia

${ }^{e}$ Department of Process Engineering, International Maritime College Oman, Suhar,322, Oman.E-mail: meisam@imco.edu.om

${ }^{f}$ School of Chemical Engineering, The University of Adelaide, South Australia, 5005, Australia

† Electronic supplementary information (ESI) available. See DOI: 10.1039/ d0ma00295j
}

Nanotechnology has enabled researchers to apply nanosize additives to improve the performance of concrete. The improvement was achieved owing to the unique properties of nanomaterials, such as their high strength, high Young's modulus, high surface area, high electrical conductivity, acceleration of calcium silicate hydrate $(\mathrm{C}-\mathrm{S}-\mathrm{H})$ gel formation and certain chemical activity. ${ }^{2,8}$ The most important challenge for the use of nanoparticles in cement mortar composites is their dispersibility. ${ }^{9}$ Poor dispersion of nanoparticles in the concrete matrix results in the creation of nanometric and millimetric porous structures with weak progress of cement hydration, leading to the penetration of sulphate and chlorine salts into the porous matrix. This will consequently lead to the formation of mico-cracks, disruption of the cement matrix and subsequent increase of the maintenance costs. ${ }^{10}$ The excellent dispersion of nanoparticles in the concrete can form a denser cementitious matrix with a low permeability level against aggressive environments.

Several studies have been conducted to investigate the properties of cementitious materials containing nanoparticles. ${ }^{2,9-22}$ 
The studies of cementitious materials containing silica $\left(\mathrm{SiO}_{2}\right)$ nanoparticles have investigated the influence of the uniform distribution of nano-silica on reducing the permeability of concrete and enhancing its physico-mechanical properties. ${ }^{10-12}$ Research on the use of metal oxide nanoparticles, such as iron oxide $\left(\mathrm{Fe}_{2} \mathrm{O}_{3}\right),{ }^{13-15}$ alumina $\left(\mathrm{Al}_{2} \mathrm{O}_{3}\right),{ }^{16}$ copper oxide $(\mathrm{CuO}),{ }^{17}$ zinc peroxide $\left(\mathrm{ZnO}_{2}\right){ }^{18}$ titanium dioxide $\left(\mathrm{TiO}_{2}\right),{ }^{2}$ and zirconium dioxide $\left(\mathrm{ZrO}_{2}\right){ }^{9}$, as well as nano-clay particles ${ }^{19,20}$ has investigated the influence of the curing method and time on the physico-mechanical properties of the self-compacting concrete. These studies have revealed that the degree of cement hydration increases with the incorporation of oxidized nanoparticles. Among the nanoparticles used in cementitious materials, $\mathrm{Fe}_{2} \mathrm{O}_{3}$ has attracted the most attention due to its high potential to interact with the free calcium hydroxide $\left(\mathrm{Ca}(\mathrm{OH})_{2}\right)$ of the cement, which can result in forming a hydration product to strengthen the mechanical properties of the concrete. Such magnetic nanoparticles can play the key role of accelerators for hydrating the cementitious product and micro-crack bridging. ${ }^{22}$

Khoshakhlagh et al. ${ }^{23}$ have studied the influence of different dosages of IO nanoparticles on the heat of hydration and water permeability of Portland cement. They found that the addition of IO nanoparticles up to $4 \mathrm{wt} \%$ increased the strength and water permeability and decreased the heat of hydration of the cement. Nazari et al. ${ }^{13-15}$ have investigated the compressive, flexural and tensile strengths of Portland cement in the presence of $0.5-2 \mathrm{wt} \%$ of IO nanoparticles. Oltulu et al. ${ }^{24,25}$ have examined the compressive strength and water permeability of concrete containing fly ash, silica, IO and alumina nanoparticles, and have found that the incorporation of IO nanoparticles led to the lowest mechanical properties in early-stages (i.e. 3- and 7-day) but the highest mechanical properties from 28 days of curing. Hui et al. ${ }^{26}$ have studied the dependency of the flexural strength of Portland cement on the IO nanoparticle dosage up to 3 and $5 \mathrm{wt} \%$. The behavior of cement paste containing IO nanoparticles at elevated temperatures has been investigated by Amer et al. ${ }^{27}$ and it has been shown that IO offers a satisfactory level of thermal durability to the plain cement paste. ${ }^{27}$

Although previous studies have made a significant contribution towards understanding the properties of cementitious materials containing IO nanoparticles, there is significant inconsistency in their results showing different effects of different IO materials on the physico-mechanical properties of cement mortar composites. More importantly, the lack of proper characterization has led to poor understanding about the influence of IO dosage on the chemistry of bonding, formation of hydration products and physico-mechanical properties of cement mortar composites. In this paper, the microstructure and mechanical properties (including compressive and flexural strengths) of a cement mortar composite containing IO nanoparticles are investigated. The purpose of this research work is to establish correlations between the physico-chemical and physico-mechanical properties of cement mortar composites in order to better understand the effect of the incorporation of IO nanoparticles on the growth and change of hydration crystals of cement as well as bonding strength of the cement mortar composite. In order to establish such correlations, cement mortar composites were prepared by incorporating a wide range of IO dosages (i.e. $0-3 \mathrm{wt} \%$ of cement). The microstructural, physico-chemical and physico-mechanical properties of the composites are characterized using scanning electron microscopy (SEM), X-ray diffraction (XRD) analysis, thermogravimetric analysis (TGA) and axial compression and flexural tests.

\section{Experimental section}

\subsection{Materials}

IO $\left(\mathrm{Fe}_{3} \mathrm{O}_{4}\right)$ nanoparticle powder, with the specifications shown in Table 1, was procured from Merck. Portland cement (CEM II-42.5) was obtained from Mazandaran Cement Factory and was used as a binder. The chemical composition of the cement determined using X-ray fluorescence is shown in Table 2. Graded river sand, with the particle size distribution provided in Table 3, was used as an aggregate in the preparation of cement mortars.

\subsection{Specimens preparation}

Four different IO concentrations were used in the preparation of mortar mixes: $0.0 \mathrm{wt} \%$ (as the control specimen), $2.0 \mathrm{wt} \%$, $2.5 \mathrm{wt} \%$ and $3.0 \mathrm{wt} \%$ of the total weight of the cement. These concentrations were determined after a careful review of the literature to establish an optimum amount of IO for flexural and compressive strength of the mortar composites. ${ }^{13-15,23-25}$ All the mixes had a water-to-cement ratio $(w / c)$ of 0.5 . The mixture proportions of the mixes are shown in Table 4.

The high-magnification micrograph of IO nanoparticle materials, which is shown in Fig. S1 (in ESI, $\dagger$ ), illustrates that the IO nanoparticles were spherical in shape with some agglomerated particles. Therefore, they were sonicated in water for $10 \mathrm{~min}$ to obtain a uniform dispersion before their introduction into the cement mortars. At first, the cement was mixed and homogenized with sand at a low speed of $50 \mathrm{rpm}$ for $5 \mathrm{~min}$. The sonicated IO was gradually added to the mix followed by mixing for another $5 \mathrm{~min}$ before the mixtures were poured into the prismatic molds with a $4 \times 4 \times 16 \mathrm{~cm}$ dimension. After pouring the mortar, a vibration machine was used to vibrate the mixture to remove air bubbles. Following demolding of the prepared specimens after $24 \mathrm{~h}$ at ambient temperature $\left(25^{\circ} \mathrm{C}\right)$

Table 1 Characteristics of iron oxide nanoparticles

\begin{tabular}{llll}
\hline $\begin{array}{l}\text { Density } \\
\left(\mathrm{g} \mathrm{cm}^{-3}\right)\end{array}$ & $\begin{array}{l}\text { Average particle } \\
\text { diameter }(\mathrm{nm})\end{array}$ & $\begin{array}{l}\text { Specific surface } \\
\text { area }\left(\mathrm{g} \mathrm{cm}^{-2}\right)\end{array}$ & Purity $(\%)$ \\
\hline 3.21 & $30>$ & 30 & 99
\end{tabular}

Table 2 Chemical composition of Portland cement (wt\% as oxides, determined using $\mathrm{X}$-ray fluorescence)

\begin{tabular}{lllllllll}
\hline $\mathrm{SiO}_{2}$ & $\mathrm{MgO}$ & $\mathrm{Na}_{2} \mathrm{O}$ & $\mathrm{K}_{2} \mathrm{O}$ & $\mathrm{SO}_{3}$ & $\mathrm{CaO}$ & $\mathrm{Fe}_{2} \mathrm{O}_{3}$ & $\mathrm{Al}_{2} \mathrm{O}_{3}$ & LOI \\
\hline 21.93 & 0.98 & 0.12 & 65.00 & 2.08 & 63.70 & 3.36 & 5.00 & 2.50
\end{tabular}


Table 3 Particle size distribution of sand

\begin{tabular}{|c|c|c|c|c|c|c|}
\hline Mesh size (mm) & 2.00 & 1.60 & 1.00 & 0.50 & 0.16 & 0.08 \\
\hline Remaining on the sieve (\%) & 0 & $7 \pm 5$ & $33 \pm 5$ & $67 \pm 5$ & $87 \pm 5$ & $99 \pm 1$ \\
\hline
\end{tabular}

Table 4 Mix proportions of the iron oxide-cement mortar composites

\begin{tabular}{lllllll}
\hline $\begin{array}{l}\text { Iron oxide } \\
\text { dosage } \\
(w \mathrm{wt})\end{array}$ & $w / c$ & $\begin{array}{l}\text { Cement } \\
\left(\mathrm{kg} \mathrm{m}^{-3}\right)\end{array}$ & $\begin{array}{l}\text { Water } \\
\left(\mathrm{kg} \mathrm{m}^{-3}\right)\end{array}$ & $\begin{array}{l}\text { Iron oxide } \\
\left(\mathrm{kg} \mathrm{m}^{-3}\right)\end{array}$ & $\begin{array}{l}\text { Sand } \\
\left(\mathrm{kg} \mathrm{m}^{-3}\right)\end{array}$ & $\begin{array}{l}\text { Super- } \\
\text { plasticizer } \\
\left(\mathrm{kg} \mathrm{m}^{-3}\right)\end{array}$ \\
\hline 0.0 & 0.5 & 592.5 & 296.25 & 0.00 & 1629.38 & 1.08 \\
2.0 & 0.5 & 592.5 & 296.25 & 11.85 & 1629.38 & 1.08 \\
2.5 & 0.5 & 592.5 & 296.25 & 14.81 & 1629.38 & 1.08 \\
3.0 & 0.5 & 592.5 & 296.25 & 17.78 & 1629.38 & 1.08 \\
\hline
\end{tabular}

and a relative humidity of $95 \%$, they were cured in a water bath until the testing day.

\subsection{Testing methods}

2.3.1 Mechanical characterization. The compression and flexure tests were conducted according to ASTM C348 ${ }^{28}$ and ASTM $\mathrm{C} 349^{29}$ on the specimens to measure their compressive and flexural strengths on 3, 7 and 28 days of curing, respectively. From each mix, three specimens were used to determine the average and uncertainty of the compressive and flexural strength measurements, using a Toni Technic instrument (Toni Technic, Germany).

2.3.2 Scanning electron microscopy (SEM). The microstructure of the mortar mixes and IO distribution in them at 28 days of curing were analyzed using a KYKY-EM3200 digital scanning electron microscope (SEM) under $26 \mathrm{kV}$. Prior to the imaging, all specimens were coated with a $10 \mathrm{~nm}$-thick platinum layer to enhance the conductivity and resolution in the SEM analysis.

2.3.3 Thermogravimetric analysis (TGA). In order to examine the influence of IO nanoparticle incorporation on the hydration properties of the cement mortar composite, thermogravimetric analysis (TGA) was performed on the 28 days-cured specimens. The specimens were kept in an alumina crucible, and a Mettler Toledo TGA testing machine was used for the analysis. In each test, approximately $30 \mathrm{mg}$ of composite was heated from room temperature to $900{ }^{\circ} \mathrm{C}$ under the flow of nitrogen with a heating rate of $10{ }^{\circ} \mathrm{C} \mathrm{min}^{-1}$. In the TGA analysis, the non-evaporable (bound) water content was used to calculate the hydration degree according to the method which has previously been described elsewhere. $^{30-32}$ The weight loss of sand was excluded in the hydration degree calculation.

2.3.4 X-ray diffraction (XRD). X-ray diffraction (XRD) was performed using an X-ray diffractometer (Rigaku MiniFlex 600, Japan), at $40 \mathrm{kV}$ and $15 \mathrm{~mA}$ in the range of $2 \theta=5-80^{\circ}$ with a scanning rate of $10{ }^{\circ} \mathrm{C} \min ^{-1}$ and $\mathrm{CuK} \alpha$ radiation $(\lambda=1.540 \AA)$, to determine the crystalline phases of the plain and IOenriched hydrated cementitious composite.

\section{Results and discussion}

\subsection{Compressive and flexural strengths}

Fig. 1 shows the compressive strength of the specimens containing different dosages of IO nanoparticles at 3, 7 and 28 days

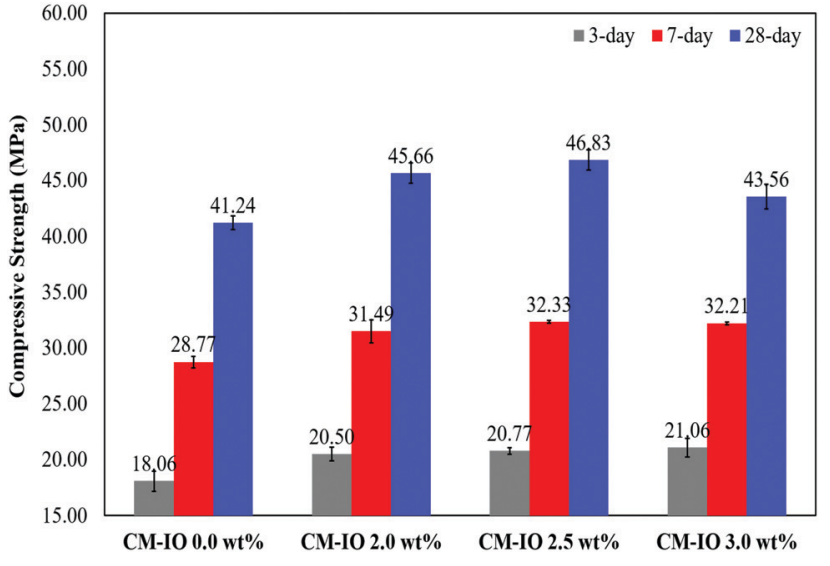

Fig. 1 The 3-, 7- and 28 day compressive strengths of cement mortars with different iron oxide contents.

of curing. As can be observed in the figure, the compressive strength of the cement mortar steadily increased with an increase in the IO nanoparticle dosage to $2.5 \mathrm{wt} \%$, but then decreased with further increase in dosage. Cement mortars containing $2.5 \mathrm{wt} \%$ IO exhibited 13, 10 and 12\% higher 3-, 7- and 28-day compressive strengths than plain cement mortar. Such increasing trend before $2.5 \mathrm{wt} \%$ dosage and dependency of the strength on IO dosage were observed for both early and longer curing times. The decrease of compressive strength with a further increase in the IO dosage from $2.5 \mathrm{wt} \%$ to $3.0 \mathrm{wt} \%$ is attributed to the agglomeration of nanoparticles at higher dosages which had a negative impact on the hydration level and bonding strength of the materials, which is discussed in the next section. However, as can be seen in Fig. 1, at a given curing age, all the specimens containing IO exhibited a higher compressive strength than the plain cement mortar.

Fig. 2 shows the 3-, 7- and 28 day flexural strengths of specimens containing different IO dosages. As can be seen in the figure, similar to the trend of the compressive strength, the flexural strength of the cement mortars increased with an increase in the IO dosage to $2.5 \mathrm{wt} \%$ but decreased with the further increase of IO dosage from $2.5 \mathrm{wt} \%$ to $3.0 \mathrm{wt} \%$. Cement mortars containing $2.5 \mathrm{wt} \%$ IO had 5, 3 and $2 \%$ higher $3-$, 7- and 28-day flexural strengths than plain cement mortar. It can be seen in the figure that cement mortars with $3.0 \mathrm{wt} \%$ IO experienced a 2, 9 and 13\% lower 3-, 7- and 28-day flexural strength than plain cement mortars. As discussed in the following section, the increase in the flexural strength with an increase in the IO dosage up to $2.5 \mathrm{wt} \%$ is because of the reinforcement effect of IO nanoparticles together with their uniform dispersion in the cement matrix, which results in a more compact microstructure compared to that of plain cement mortar. However, at IO dosages higher than $2.5 \mathrm{wt} \%$, the IO nanoparticles were agglomerated with poor dispersion which negatively affected the bonding strength of the composite. 


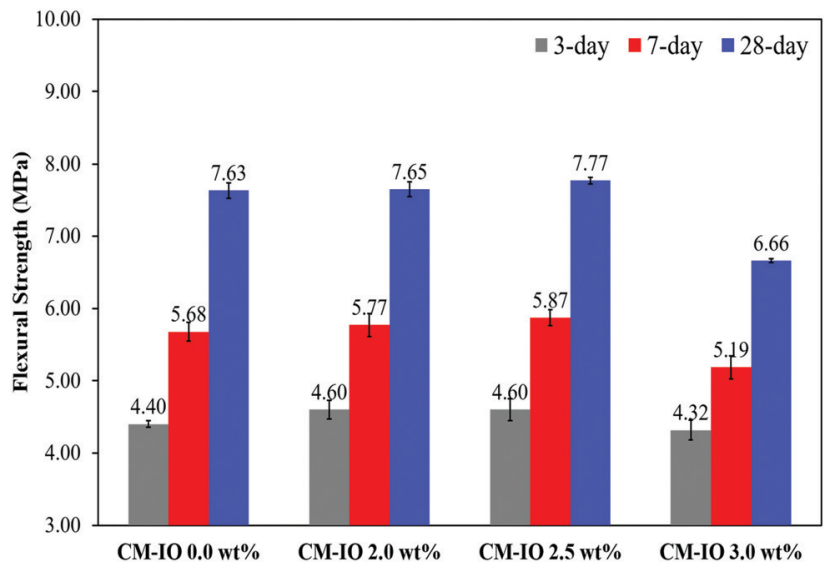

Fig. 2 The 3-, 7- and 28-day flexural strengths of cement mortars with different iron oxide contents.

\subsection{Analysis of microstructure, hydration degree and crystalline phases}

Fig. 3a-d show the high-magnification SEM images of the specimens with IO dosages of $0.0,2.0,2.5$ and $3.0 \mathrm{wt} \%$, respectively. As can be seen in Fig. 3a, the microstructure of plain cement mortar contained micropores and gaps, which were partially filled with cement flat random-shape hydration products. The formation of some micro-cracks is also evident in the plain cement mortar. It can be seen in Fig. $3 \mathrm{~b}$ that, at an IO dosage of $2.0 \mathrm{wt} \%$, the flat random-shape hydration crystals shown in Fig. 3a were replaced with long needle-shaped hydration products, which could play a decisive role in the permeability of concrete. It can also be seen in the figure that $2.0 \mathrm{wt} \%$ IO dosage was not enough to prevent the formation of microcracks, as spotted in the red rectangles in the figure. However, the cement mortar with $2.0 \mathrm{wt} \%$ IO exhibited a lower density of micro-cracks than the plain cement mortar. This observation is in agreement with previous studies that reported, when a low dosage of nanoparticles is uniformly distributed in the cement mortar matrix, nanoparticles as a nuclei firmly bond with hydrated cement and prevent the large growth of $\mathrm{Ca}(\mathrm{OH})_{2}$ crystals. ${ }^{27}$ As can be seen in Fig. 3c, the cement mortar with $2.5 \mathrm{wt} \%$ IO had a more compact microstructure with no microcracks compared to that with $2.0 \mathrm{wt} \% \mathrm{IO}$, which indicates that an increase in the nanoparticle dosage has led to strong bridging between $\mathrm{C}-\mathrm{S}-\mathrm{H}$ crystals and $\mathrm{IO}$ particles. This can speed up the hydration to contribute to the chemical resistance of mortar against chloride penetration and carbonation. ${ }^{27}$ As can be observed in Fig. 3d, the cement mortar with $3.0 \mathrm{wt} \%$ IO exhibited a lesser amount of random- or needle-shaped hydration products, which is attributed to the agglomeration of nanoparticles with high dosage, due to the strong magnetic attraction, van der Waals forces and high energy surface of IO. ${ }^{33}$ Such agglomeration leads to trapping of some oxygen groups at the surface of IO nanoparticles, making them inaccessible to wettability of the matrix without contributing towards the hydration and interaction with the $\mathrm{C}-\mathrm{S}-\mathrm{H}$ bonds. ${ }^{34}$ Fig. 3e and $\mathrm{f}$ show the scheme of the microstructure of cement mortars with
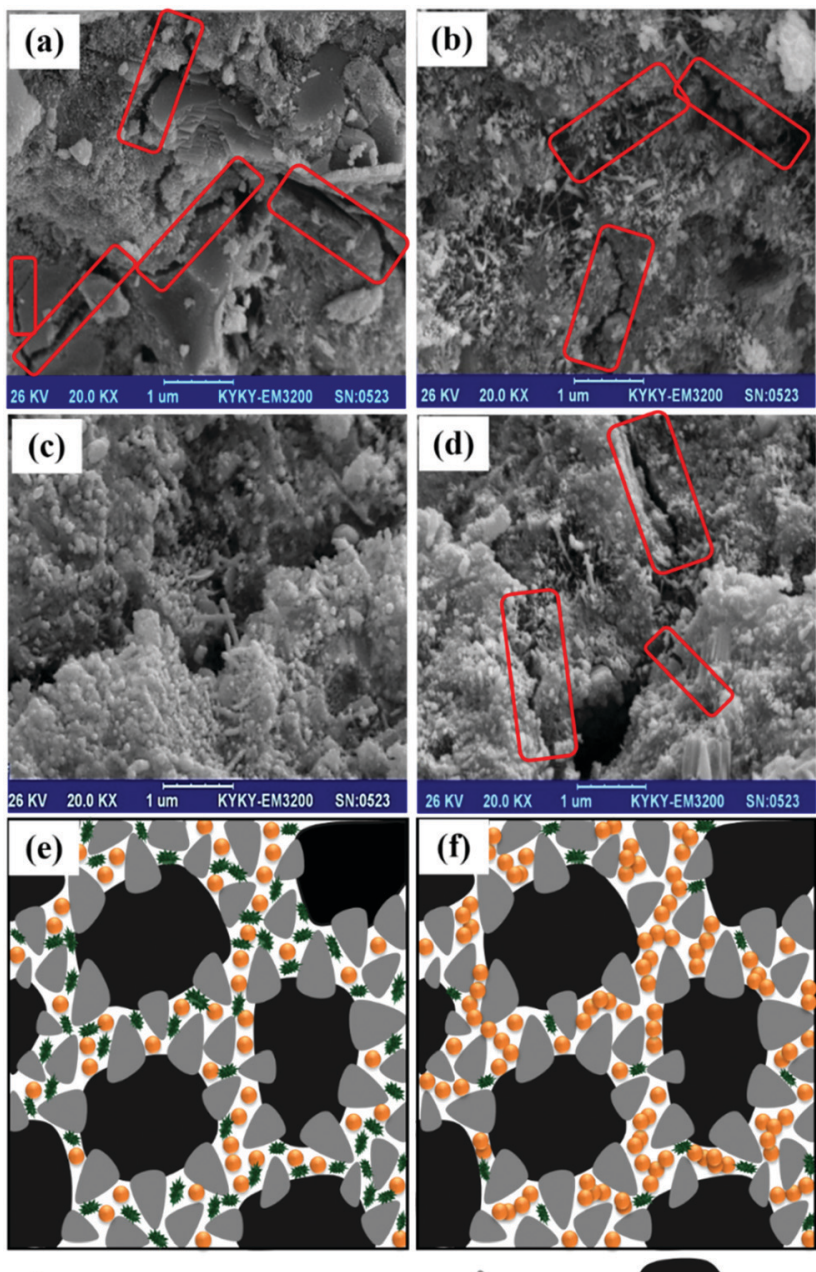

C-S-H IO nanoparticle

Cement

Sand

Fig. 3 High-magnification SEM images of cement mortars with different iron oxide contents: (a) $0.0 \mathrm{wt} \%$, (b) $2.0 \mathrm{wt} \%$, (c) $2.5 \mathrm{wt} \%$ and (d) $3.0 \mathrm{wt} \%$. Schematic visualization of (e) uniformly dispersed iron oxide nanoparticles and (f) agglomerated iron oxide nanoparticles in the cement mortar matrix.

uniformly dispersed and agglomerated IO nanoparticles, respectively. As can be seen in the figure, the formation of $\mathrm{C}-\mathrm{S}-\mathrm{H}$ in the cement mortar with uniform IO dispersion was substantially higher than that with agglomerated IO.

The influence of the IO dosage on the hydration degree of IO-cement mortar composites was evaluated using the TGA plots shown in Fig. 4. The hydration degree values were calculated using the method which has previously been described elsewhere,,$^{30-32}$ and the equation is provided in the ESI. $\dagger$ As can be seen in the figure, the hydration degree of the composite increased with an increase in the IO dosage up to $2.5 \mathrm{wt} \%$. The dependency of hydration degree to the IO dosage agrees with the previous study on the use of IO in cement paste. ${ }^{22}$ The hydration degree of the composites with $2.0 \mathrm{wt} \%$ and $2.5 \mathrm{wt} \%$ IO were $28 \%$ and $32 \%$ higher than that of the plain composite, respectively. The highest hydration and wettability achieved with $2.5 \mathrm{wt} \%$ IO can be attributed to the highest yield of $\mathrm{C}-\mathrm{S}-\mathrm{H}$ products observed in the SEM image shown in Fig. 3c. It can also be 


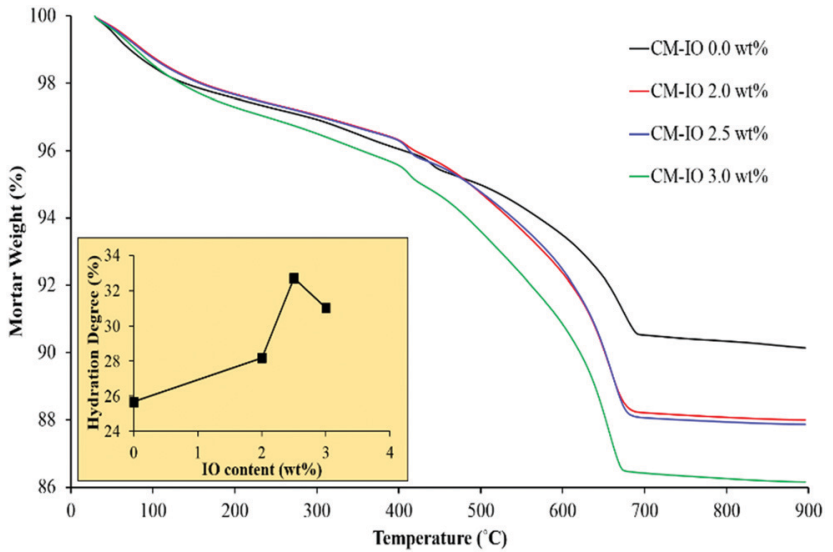

Fig. 4 TGA curves of iron oxide-cement composites with different iron oxide contents. The inset is the hydration degree of the specimens.

seen in Fig. 4 that a further increase in the IO dosage from $2.5 \mathrm{wt} \%$ to $3.0 \mathrm{wt} \%$ resulted in a decrease in the wettability and hydration degree of the composite; however, it was still $31 \%$ higher than that of the plain composite. The decrease in the hydration degree of the composite after $2.5 \mathrm{wt} \%$ IO dosage can be attributed to the agglomeration of nanoparticles (as schematically depicted in Fig. 3f), which restricted the penetration of the water molecules into IO-cement interfaces, thereby reducing the yield of $\mathrm{C}-\mathrm{S}-\mathrm{H}$ products.

The XRD spectra of composites with different IO dosages are shown in Fig. 5. The most dominant peaks at the scattering angle $(2 \theta)$ of $22^{\circ}$ and $28^{\circ}$ are because of the presence of quartz as the only crystalline phase of the sand. ${ }^{35,36}$ Characteristic peaks of $29.6^{\circ}, 45.7^{\circ}, 50.3^{\circ}$ and $55.2^{\circ}$ correspond to $\mathrm{Ca}(\mathrm{OH})_{2}$ $(\mathrm{C}-\mathrm{H})$ and $\mathrm{C}-\mathrm{S}-\mathrm{H}$ products. Peaks of tricalcium silicate $\left(\mathrm{C}_{3} \mathrm{~S}\right)$ and dicalcium silicate $\left(\mathrm{C}_{2} \mathrm{~S}\right)$ were distinguished as the progression of the hydration process to form $\mathrm{C}-\mathrm{H}$ and $\mathrm{C}-\mathrm{S}-\mathrm{H}$ products. $^{37}$ Such progress in the hydration process leads to the enhancement of the strength as well as volume stability of the cementitious materials. ${ }^{34}$ The XRD peaks shown for composites with 2.0, 2.5 and $3.0 \mathrm{wt} \%$ IO (indicated by b, c and d, respectively) at the scattering angles of about $36^{\circ}, 57.5^{\circ}$ and
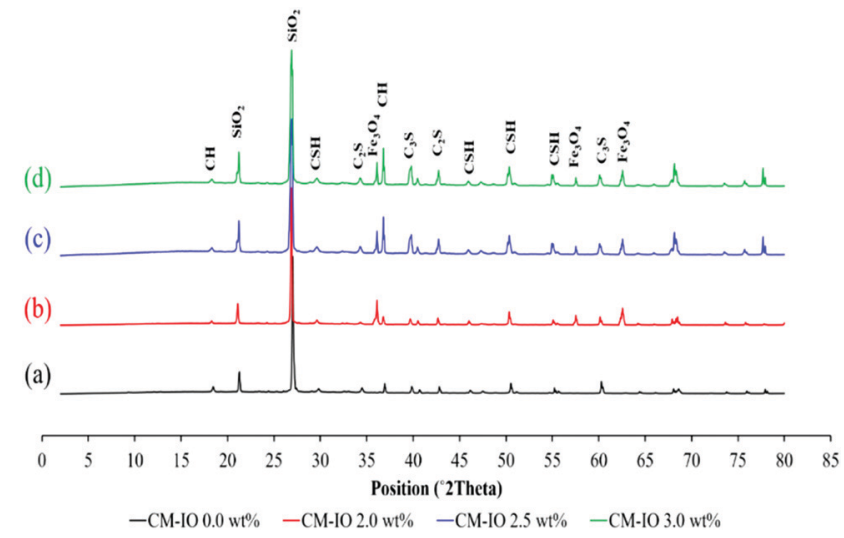

Fig. 5 XRD patterns of iron oxide-cement mortar composites with different iron oxide contents. $62.5^{\circ}$ correspond to the presence of IO nanoparticle crystals. ${ }^{8,38,39}$ As can be observed in the figure, the control specimen with $0.0 \mathrm{wt} \%$ IO did not have the $36^{\circ}, 57.5^{\circ}$ and $62.5^{\circ}$ characteristic peaks, confirming the absence of IO nanoparticles in the plain mortar composite. It can also be seen in the figure that the composite with $2.0 \mathrm{wt} \%$ IO exhibited the largest cumulative intensity of characteristic peaks corresponding to the $\mathrm{C}-\mathrm{H}$ and $\mathrm{C}-\mathrm{S}-\mathrm{H}$ products. This, in agreement with the SEM and TGA results, further confirms that increasing the IO dosage in the cement mortar composites enhances the wettability and hydration of the composite leading to higher strengths. It can be seen in Fig. 5 that the cumulative intensity of the hydration peaks for the specimen with an IO dosage of $2.0 \mathrm{wt} \%$ was larger compared to that of plain mortar, which is because of up-taking more water and the formation of more hydration products, confirming the role of IO nanoparticles in the enhancement of the bonding properties, crystallization and physico-mechanical properties.

\section{Conclusions}

This paper has presented the first study on the physico-chemical properties of cement mortar composites containing IO nanoparticles. The influence of IO dosage on the properties of IO-cement mortar composites has been studied considering IO dosages of $0.0,2.0,2.5$ and $3.0 \mathrm{wt} \%$ by weight of cement. It was demonstrated that increasing the IO dosage up to $2.5 \mathrm{wt} \%$ results in an increase in the compressive and flexural strengths of the cement mortar composite; however, further increase from $2.5 \mathrm{wt} \%$ to $3.0 \mathrm{wt} \%$ leads to a decreases in the strength. The cement mortar composite containing the optimal IO dosage of $2.5 \mathrm{wt} \%$ exhibited $12 \%$ and $2 \mathrm{wt} \%$ higher 28 day compressive and flexural strengths than those of plain cement mortar, respectively. It was found that the IO nanoparticles not only prevent the formation and propagation of micro-cracks, but also contribute to the improvement of the accessibility of the water molecules to the IO oxygen groups and cement $\mathrm{C}-\mathrm{S}-\mathrm{H}$. Based on the SEM images, at IO dosages of up to $2.5 \mathrm{wt} \%$, no agglomeration has been observed in the microstructure of the composite, but further increase in the IO dosage developed agglomerated IO nanoparticles and increased density of micro-cracks in the cement matrix. The TGA and XRD analyses also showed that the cement mortar composite with $2.5 \mathrm{wt} \%$ IO experienced the highest hydration degree and cumulative hydration product crystalline phases. These results further confirmed that the IO dosage of $2.5 \mathrm{wt} \%$ is the optimum to prevent the agglomeration of nanoparticles, resulting in the highest strengths.

\section{Conflicts of interest}

There are no conflicts to declare.

\section{Acknowledgements}

The authors gratefully acknowledge the assistance from Mazandaran Cement Company, Iran, for the material preparation 
and mechanical tests. The authors also thank School of Chemical Engineering at the University of Adelaide for supporting in characterizations of the materials.

\section{Notes and references}

1 A. Bahari and A. Ramzannejad, Int. J. Mod. Phys. B, 2012, 26, 1250080.

2 D. Feng, N. Xie, C. Gong, Z. Leng, H. Xiao, H. Li and X. Shi, Ind. Eng. Chem. Res., 2013, 52, 11575-11582.

3 A. Bahari, U. Robenhagen, P. Morgen and Z. Li, Phys. Rev. B: Condens. Matter Mater. Phys., 2005, 72, 205323.

4 H. Li, H.-g. Xiao, J. Yuan and J. Ou, Composites, Part B, 2004, 35, 185-189.

5 K. Sobolev and M. F. Gutiérrez, Am. Ceram. Soc. Bull., 2005, 84, 14.

6 P. Bartos, J. J. Hughes, P. Trtik and W. Zhu, Nanotechnology in construction, Royal Society of Chemistry, 2004.

7 Z. Bittnar, P. Bartos, J. Nemecek, V. Smilauer and J. Zeman, Nanotechnology in Construction, Springer-Verlag Berlin Heidelberg, Prague, Czech Republic, 2009, p. 438.

8 P. Sikora, E. Horszczaruk, K. Cendrowski and E. Mijowska, Nanoscale Res. Lett., 2016, 11, 182.

9 A. Nazari and S. Riahi, J. Compos. Mater., 2012, 46, 1079-1090. 10 B.-W. Jo, C.-H. Kim, G.-H. Tae and J.-B. Park, Constr. Build. Mater., 2007, 21, 1351-1355.

11 A. N. Givi, S. A. Rashid, F. N. A. Aziz and M. A. M. Salleh, Composites, Part B, 2010, 41, 673-677.

12 L. Senff, J. A. Labrincha, V. M. Ferreira, D. Hotza and W. L. Repette, Constr. Build. Mater., 2009, 23, 2487-2491.

13 A. Nazari, S. Riahi, S. Riahi, S. F. Shamekhi and A. Khademno, Am. J. Sci., 2010, 6, 102-106.

14 A. Nazari, S. Riahi, S. Riahi, S. F. Shamekhi and A. Khademno, Am. J. Sci., 2010, 6, 90-93.

15 A. Nazari and S. Riahi, Mater. Des., 2011, 32, 3966-3979.

16 A. Nazari, S. Riahi, S. Riahi, S. F. Shamekhi and A. Khademno, Am. J. Sci., 2010, 6, 94-97.

17 A. Nazari and S. Riahi, Sadhana, 2011, 36, 371.

18 A. Nazari and S. Riahi, Composites, Part B, 2011, 42, 167-175. 19 T.-P. Chang, J.-Y. Shih, K.-M. Yang and T.-C. Hsiao, J. Mater. Sci., 2007, 42, 7478-7487.
20 W.-Y. Kuo, J.-S. Huang and C.-H. Lin, Cem. Concr. Res., 2006, 36, 886-895.

21 E. Garboczi and D. Bentz, Constr. Build. Mater., 1996, 10, 293-300.

22 M. Amin, S. El-Gamal and F. Hashem, J. Therm. Anal. Calorim., 2013, 112, 1253-1259.

23 A. Khoshakhlagh, A. Nazari and G. Khalaj, J. Mater. Sci. Technol., 2012, 28, 73-82.

24 M. Oltulu and R. Şahin, Mater. Sci. Eng., A, 2011, 528, 7012-7019.

25 M. Oltulu and R. Şahin, Energy Build., 2013, 58, 292-301.

26 H. Li, H.-g. Xiao and J.-p. Ou, Cem. Concr. Res., 2004, 34, 435-438.

27 A. A. Amer, T. M. El-Sokkary and N. I. Abdullah, HBRC J., 2015, 11, 299-305.

28 ASTM C348-14, Standard Test Method for Flexural Strength of Hydraulic-Cement Mortars, West Conshohocken, PA, 2014.

29 ASTM C349-14, Standard Test Method for Compressive Strength of Hydraulic-Cement Mortars (Using Portions of Prisms Broken in Flexure), West Conshohocken, PA, 2014.

30 A. Gholampour, M. V. Kiamahalleh, D. N. Tran, T. Ozbakkaloglu and D. Losic, RSC Adv., 2017, 7, 55148-55156.

31 A. Gholampour, M. Valizadeh Kiamahalleh, D. N. Tran, T. Ozbakkaloglu and D. Losic, ACS Appl. Mater. Interfaces, 2017, 9, 43275-43286.

32 M. V. Kiamahalleh, A. Gholampour, D. N. H. Tran, T. Ozbakkaloglu and D. Losic, Constr. Build. Mater., 2020, 250, 118832.

33 T. Xia, J. Wang, C. Wu, F. Meng, Z. Shi, J. Lian, J. Feng and J. Meng, CrystEngComm, 2012, 14, 5741-5744.

34 A. A. Keller, H. Wang, D. Zhou, H. S. Lenihan, G. Cherr, B. J. Cardinale, R. Miller and Z. Ji, Environ. Sci. Technol., 2010, 44, 1962-1967.

35 F. Raupp-Pereira, D. Hotza, A. M. Segadães and J. A. Labrincha, Ceram. Int., 2006, 32, 173-179.

36 N.-u. Amin, S. Alam and S. gul, RSC Adv., 2015, 5, 6079-6084.

37 R. Wang, L. Yao and P. Wang, Constr. Build. Mater., 2013, 41, 538-544.

38 F. N. Sayed and V. Polshettiwar, Sci. Rep., 2015, 5, 9733.

39 L. Zhuang, W. Zhang, Y. Zhao, H. Shen, H. Lin and J. Liang, Sci. Rep., 2015, 5, 9320. 